\title{
PARA UMA VISÃO COMPLEXA DO BULLYING HOMOFÓBICO: DESOCULTANDO O QUOTIDIANO DA HOMOFOBIA NAS ESCOLAS ${ }^{1}$

\author{
Hugo M. Santos* Sofia Marques da Silva** Isabel Menezes
}

\section{Resumo}

Apesar do crescente interesse pela investigação LGBTI, em Portugal são escassos os estudos sobre bullying homofóbico. Este artigo explora as representações e as experiências de estudantes do ensino secundário sobre bullying homofóbico, com recurso a 36 grupos de discussão focalizada com 232 raparigas e rapazes em 12 escolas públicas do Norte de Portugal. Constata-se a incapacidade do conceito de bullying homofóbico em abarcar todas as formas de violência homofóbica e heteronormativa da e na escola. A maior expressividade do fenómeno relaciona-se com os seus processos de construção da masculinidade no contexto das culturas juvenis, cuja incidência quotidiana nos desafia a questionar as oportunidades para a construção de uma cidadania inclusiva da diversidade sexual na escola.

Palavras-chave: Escola; bullying; homofobia; masculinidade.

\section{Abstract \\ Towards a complex vision of homophobic bullying: Unveiling daily homophobia in schools \\ Despite the growing interest in LGBTI research, in Portugal there are few studies on homophobic bullying, especially with a qualitative focus and involving a critical reapprai- sal of the concept. This paper explores the representations and experiences on homophobic bullying and sexual diversity of 232 young students (boys and girls), using focus group}

Este trabalho foi realizado no quadro do Programa de Doutoramento FCT em Ciências da Educação da Universidade do Porto, financiado por fundos nacionais, através da Fundação para a Ciência e a Tecnologia, IP, e pelo Fundo Social Europeu (FSE), através do Programa Operacional do Capital Humano (POCH) do Portugal 2020. Hugo M. Santos é apoiado através de uma bolsa de doutoramento com a ref. ${ }^{a} \mathrm{PD} / \mathrm{BD} / 52467 / 2014$. Foi ainda apoiado por fundos nacionais através da FCT - Fundação para a Ciência e a Tecnologia, I.P., no âmbito do Programa Estratégico do CIIE, com a referência «UID/CED/00167/2013».

* $\quad$ Centro de Investigação e de Intervenção Educativas (CIIE), Faculdade de Psicologia e de Ciências da Educação (FPCE), Universidade do Porto, Portugal

Endereço eletrónico: hmiguel_s@hotmail.com.

** Centro de Investigação e de Intervenção Educativas (CIIE), Faculdade de Psicologia e de Ciências da Educação (FPCE), Universidade do Porto, Portugal

Endereço eletrónico: sofiamsilva@fpce.up.pt

*** Centro de Investigação e de Intervenção Educativas (CIIE), Faculdade de Psicologia e de Ciências da Educação (FPCE), Universidade do Porto, Portugal

(Autora para quem a correspondência relativa a este artigo deve ser enviada)

Endereço eletrónico: imenezes@fpce.up.pt

Endereço Postal: CIIE, FPCE, Universidade do Porto, Rua Alfredo Allen, 4200-392 Porto, Portugal 
discussion in 12 public secondary schools in the North of Portugal. As in other studies, our data suggests the inability of the concept of «homophobic bullying» to include all the diversity of forms of homophobic and heteronormative violence within and of the school. The expression of homophobia is strongly related with juvenile cultures and processes of masculinity construction, a phenomenon with a daily prevalence that challenges us to question what are the real opportunities for the construction of a citizenship that includes sexual diversity in schools.

Keywords: School; bullying; homophobia; masculinity.

\begin{abstract}
Resumen
Hacia una visión compleja del bullying homofóbico: Revelando la homofobia diaria en las escuelas

A pesar del creciente interés por la investigación LGBTI, en Portugal son escasos los estudios realizados sobre el bullying homofóbico. Este documento explora las representaciones y las experiencias de estudiantes jóvenes de secundaria sobre el bullying homofóbico, con la participación de 232 chicos y chicas en 36 grupos de discusión focalizada de 12 escuelas públicas del Norte de Portugal. Los datos obtenidos constatan la incapacidad del concepto de «bullying homofóbico» para abarcar todas las formas de violencia homofóbica y heteronormativa de la y en la escuela. La expresión de homofobia está fuertemente relacionada con la cultura juvenil y con los procesos de construcción de masculinidad, cuya incidencia cotidiana nos desafía a cuestionar las oportunidades para la construcción de una ciudadanía inclusiva sobre la diversidad sexual en las escuelas.
\end{abstract}

Palabras clave: Escuela; bullying; homofobia; masculinidad

\title{
Introdução
}

A escola sempre se apresentou como um dos contextos institucionais de educação mais regulatórios e normativos, quer ao nível do género, quer ao nível da sexualidade (Meyer 2010). Com as missões delegadas pela modernidade, tanto de transmissão e reprodução, como de fabricação do «cidadão ideal» (Habermas 1995), dimensões como corpo, género e/ou sexualidade tendem a ser vistas como «subterfúgios» (Louro 2001; Junqueira 2009). Desde a década de 1990, quer o seu caráter normativo, quer o seu modelo fictício de «aluno ideal» (masculino, branco, de classe média, heterossexual, fisicamente eficiente, etc.) têm sido questionados, defendendo a integração de valores antidiscriminatórios nas suas políticas e práticas (Cardona et al. 2015).

As perspetivas lésbicas, gays, bissexuais, transgénero e intersexo (LGBTI), têm também denunciado o caráter homofóbico e heteronormativo da instituição a diversos níveis, seja o preconceito, a discriminação e a violência nas relações interpessoais (e.g., bullying), a negligência na prevenção e/ou eliminação dessa mesma violência ou um certo silenciamento de tópicos relativos à diversidade sexual a nível curricular (Junqueira 2009). Portugal não é exceção. Nos últimos anos, ao se assegurar o princípio constitucional da não-discriminação no plano da lei, na 
esteira do que tem sido a política contemporânea progressista ocidental, tem-se reconhecido «igualdade de direitos» para pessoas LGBTI no sentido de uma cidadania plena (Carneiro e Menezes 2007) que se estendeu também à área da educação escolar - vd. a lei da Educação Sexual (N. ${ }^{\circ}$ 60/2009) ou o Estatuto do Aluno (n. ${ }^{\circ}$ 51/ 2012). No entanto, apesar do incremento da pesquisa sobre tópicos LGBTI, em Portugal tende a persistir uma certa invisibilidade sobre estas questões no campo da educação (escolar) (Rodrigues et al. 2016), que não estará certamente desligada dos tabus que os contextos escolares não só nutrem com o «corpo» e com a «sexualidade», dois tópicos «marginalmente posicionados» (Silva 2010: 98) no campo teórico da educação, especialmente no que concerne a «homossexualidade».

Nos últimos dez anos, tem-se utilizado a expressão «bullying homofóbico» como um denominador discursivo para explicar processos de preconceito, discriminação e violência homofóbica na escola (Monk 2012; Pascoe 2013). Enquanto na literatura, o bullying é geralmente definido como uma violência entre pares caraterizada por intencionalidade em magoar, repetição e poder diferencial entre os elementos envolvidos (Furlong et al. 2010), a sua associação à «homofobia» remete, como resume Junqueira, para uma «força desumanizadora» $(2009,37)$ contra aqueles/as que não seguem - ou se julga não seguirem - um desejo, uma identidade, estilos de vida ou práticas afetivas e/ou sexuais de cariz heterossexual. Vários estudos têm demonstrado a prevalência, as causas e as consequências do bullying homofóbico aos mais variados níveis (cf. Rivers 2011; UNESCO 2012; Poteat et al. 2013), salientando a necessidade de mais pesquisa e intervenção. Também no contexto nacional existem já alguns estudos sobre o fenómeno (cf. António et al. 2012; Costa et al. 2015; Rodrigues et al. 2016) mas, como lembram Nogueira e Oliveira (2010), ainda existe pouco conhecimento, sobretudo sobre o que os/as jovens têm a dizer.

Tem-se, contudo, criticado a opção pela designação de «bullying homofóbico» pelo seu essencialismo (Monk 2012). Em primeiro lugar, o conceito parece ser incapaz de ilustrar, descrever e explicar todas as formas de violência homofóbica (e, sobretudo, heteronormativa) da e na escola que não podem ser confinadas a uma noção restritiva e monolítica de bullying (Formby 2015), mas podem envolver formas de violência heteronormativa ou institucional da escola (e.g., negligência) (Formby 2015). Como salienta Pascoe (2013), a noção de bullying parece referir-se mais a processos circunstanciais de agressão, esquecendo-se de uma abordagem mais sistemática e estrutural sobre os processos opressivos de discriminação. Em segundo lugar, o termo bullying homofóbico parece remeter para um determinado tipo de bullying contra homossexuais. Parece que basta «ser-se» gay ou lésbica para se sofrer bullying (Monk 2012), o que contribui para uma produção discursiva da «identidade homossexual» potencialmente negativa e em risco que não corresponde à realidade de várias pessoas LGBTI, a começar pelo facto de essa identidade ter que ser expressa ou, pelo menos, simbolicamente sugerida.

Por estas razões, alguns/mas investigadores/as sugerem diferentes terminologias. Minton et al. (2008), por exemplo, identificam dois subtipos de bullying 
homofóbico: um tipo de bullying indireto, a que chamam de «bullying heteronormativo», que deriva do ambiente heteronormativo da escola (i.e., onde se espera que toda a gente seja, deva ser ou goste de ser tomada como heterossexual até prova do contrário). É um subtipo de bullying menos reconhecido como tal e, por isso, raramente desafiado pelos/as educadores/as. Um outro subtipo é o «bullying baseado na orientação sexual» que envolve a discriminação ativa e direta de pessoas reconhecidas como «LGBTI», e corresponde ao que habitualmente preenche o imaginário do que é o «bullying homofóbico».

Ainda que muitas vezes essas interseções entre género e sexualidade possam ser olhadas de modo analiticamente separáveis - uma coisa são expressões de feminilidade ou masculinidade, outra são os dinamismos do desejo ou conduta sexual -, a questão de «género» é central na forma como o bullying é ou não acionado (Butler 1990; Meyer 2008). Criticando a noção de bullying pelo esquecimento da sua dimensão "genderizada», Meyer (2008), em vez de bullying, propõe o termo «assédio genderizado», analisando três subtipos do mesmo: violência (hetero) sexual, violência homofóbica e violência transfóbica. Por sua vez, Pascoe (2013) relembra que o bullying homofóbico está mais relacionado com processos de socialização para a masculinidade, não tendo necessariamente como alvo uma identidade (homo)sexual.

É importante não esquecer que a teorização sobre «homofobia» tem feito um longo caminho, que vai desde um certo abandono de posições mais intrapsíquicas até a uma compreensão dos processos de opressão contra as «minorias» sexuais como estruturais e sistemáticos (Carneiro e Menezes 2007; Junqueira 2009). O estudo que aqui se apresenta tenta aprofundar estas questões usando um desenho de natureza qualitativa com recurso a grupo focais em escolas secundárias: se o bullying homofóbico se tornou um «objeto discursivo» (Monk 2012), é então necessário ouvir o que os/as alunos/as têm a dizer sobre o fenómeno e a forma como ele afeta a sua vida na escola.

\section{Metodologia}

Este artigo dá conta de uma pesquisa qualitativa sobre bullying homofóbico que decorreu entre 2015 e 2017. Realizaram-se 36 grupos de discussão focalizada com 232 jovens maioritariamente heterossexuais (126 raparigas e 106 rapazes, com idades entre os 16 e os 18 anos), em 12 escolas do ensino secundário, públicas e urbanas, do Norte centro e litoral de Portugal. A escolha de «jovens alunos/as» como participantes tem uma dupla função: sociologicamente são parte na construção social da comunidade educativa e metodologicamente são sujeitos que sabem mais sobre uma realidade que se visa compreender melhor (Silva 2010).

Num primeiro contacto com as escolas, esclareceu-se a natureza da pesquisa com a direção da escola para obter o consentimento para a realização dos grupos focais; a direção contactou com os/as diretores/as de turma e foram estes/as que 
declararam o interesse em envolver a sua turma e selecionaram os/as participantes, tendo apenas sido pedido para serem da mesma turma (critério homogéneo) e de grupos mistos quanto ao género (critério heterogéneo), com 4 a 10 elementos por grupo, como recomendado pela literatura (Bloor et al. 2001). Apesar de não se ter inquirido a orientação sexual dos/as participantes, por óbvios motivos éticos, assume-se, por razões estatísticas, que seriam maioritariamente heterossexuais. No entanto, é de destacar esta dupla posição entre, por um lado, a partilha de uma identidade heterossexual socialmente privilegiada e potencialmente opressiva e, por outro lado, a necessidade de ultrapassar o binómio «homo/hetero» tendo em consideração um trabalho conjunto na promoção do respeito pela diversidade sexual.

Em termos de dinamização dos grupos, a discussão iniciou-se com uma forma de quebrar o gelo que possibilitasse a apresentação de cada um/a (e.g., nome, idade) e a exibição de um vídeo como motor da discussão (e.g., «Dislike Bullying Homofóbico»). A discussão foi estruturada em torno de um guião com três temas principais (bullying homofóbico, diversidade sexual, Educação Sexual) em que o bullying homofóbico era o primeiro a ser abordado. Optou-se por uma «abordagem de nomeação» (Furlong et al. 2010) em que o bullying era tratado como um objeto discursivo sem definição a posteriori (como no vídeo) ainda que, ao mesmo tempo, se procurasse explorar definições próprias sobre o conceito.

A opção pelos grupos focais deveu-se a uma conceção comunitária da realidade escolar que integra a ideia de que os problemas da comunidade devem ser discutidos entre todos/as do modo mais democrático possível. Ainda que a discussão em situação coletiva de tópicos particularmente sensíveis exija algum cuidado, como salientam Farquhar e Das (1999), tudo depende da forma como se aborda o assunto, não se podendo correr o risco de, sob pretexto ético, silenciar um debate sobre essas problemáticas, sobretudo quando elas já estão patentes nas políticas públicas. Pelo seu caráter coletivo, os grupos focais têm ainda a vantagem de possibilitar aos sujeitos uma análise reflexiva sobre os seus pensamentos e práticas, o que, por sua vez, implica reconsiderar potenciais empoderamentos para a ação (Wilkinson 1999).

Quanto ao método de análise, recorreu-se à análise temática que foi essencial para organizar uma grande quantidade de dados e aceder a padrões de regularidade dos significados (Braun e Clarke 2006). Todo o material foi transcrito, tendo sido objeto de uma leitura global que gerou a identificação de temas predominantes emergentes do material, que, num processo iterativo, foram sendo estabilizados em temas principais. São esses temas que, no que concerne às representações do bullying homofóbico, serão apresentados e analisados neste artigo. Os excertos resultam da condensação de significados que se tornaram dominantes e que são suficientemente ilustrativos de cada tema, incluindo as interações entre participantes.

Não se pode deixar de considerar alguns aspetos éticos tidos em conta na pesquisa: pedidos de autorização às instituições e ao(s)/à(s) encarregado(s)/a(s) de 
educação, criação de condições para a participação voluntária e equilibrada, em que cada participante pudesse expressar a sua opinião num ambiente confortável e de respeito mútuo, garantia não só do anonimato (relativo) das instituições e jovens (e.g., deram-se nomes de cores às escolas), mas também da devolução dos dados e posterior discussão, etc.

\section{O bullying homofóbico como expressão da masculinidade e o ritual do insulto}

Sendo entendido pelos/as jovens como um particular tipo de bullying contra homossexuais, a existência e prevalência do bullying homofóbico exige um determinado reconhecimento público da identidade sexual de outro. Ora, muitas vezes essa identidade não é possível de ser assumida, seja porque os/as jovens estão em processos de descoberta da sua orientação sexual, seja porque está oculta precisamente pela potencial violência que a sua desocultação pode gerar, daí que a noção de bullying homofóbico tenha que ser entendida em termos de «bullying heteronormativo» (Minton et al., 2008), estando relacionado com as socializações dominantes dos rapazes e dirigindo-se fundamentalmente a qualquer um (Pascoe 2013). Como explica Rui, de modo curioso: «Não há bullying homofóbico aqui na escola porque não há gays porque se houvesse [gays] havia [bullying homofóbico] de certeza!» (GDF1, Escola Roxa).

O que a pesquisa revela, e os/as jovens reconhecem, é que uma parte substancial daquilo que se entende por «bullying homofóbico» está geralmente relacionado com processos de construção da masculinidade no contexto das culturas juvenis, manifestando-se não só, mas sobretudo, com os usos de linguagem homofóbica, sob a forma de epítetos nas interações entre rapazes (Pascoe 2007, 2013; Poteat e Rivers 2009). Uma boa parte dos estudos sobre bullying e sobre bullying homofóbico tem esclarecido como a linguagem - comentários, piadas, insultos, etc. - constitui uma das formas de bullying mais comuns (Rivers 2011; António et al. 2012; Poteat et al. 2013; Costa et al. 2015; Rodrigues et al. 2016). O excerto seguinte é seguramente revelador:

Rodolfo - Não é bem bullying; é tipo, bocas, uns comentários: «és mesmo maricas!»

Hugo - Mas, por exemplo, é muito comum os rapazes chamarem-se, por exemplo, de maricas?

[o grupo sorri efusivamente]

Rodolfo - Normal? É mais do que normal! É o prato do dia! (GDF1, Escola Azul)

Qualquer exploração das variáveis «sexo/género» em relação às atitudes perante os dois tipos de homossexualidade (feminina e masculina) tem também evidenciado que é na linha que une masculinidade heterossexual e homossexua- 
lidade masculina que a homofobia é mais expressiva, o que tem contribuído para se produzir um modelo explicativo dominante da homofobia como um medo fantasmagórico da masculinidade heterossexual a possibilidades homossexuais (Junqueira 2009). No contexto escolar, a relação entre os processos de construção performativa de uma masculinidade simbolicamente heterossexual e o repúdio diretamente proporcional à homossexualidade masculina no contexto da escola geralmente tendo como centro gravitacional aquilo que Connell (1995) denominou celebremente de «masculinidade hegemónica» - tem sido descrito e explorado por vários/as autores/as (Rocha e Ferreira 2002; Kimmel e Mahler 2003; Pascoe 2007; Silva e Araújo 2007; Pereira 2009).

Nesta lógica, a homofobia resultaria de um processo simbólico onde os rapazes (geralmente heterossexuais) se demarcam constantemente de possibilidades homossexuais (que eles entendem como negativas), nomeadamente a partir do insulto. Por extensão, a invocação da «identidade homossexual» aparece então como um «Outro fantasmagórico», tido como «efeminado», a quem se atribuem significados desqualificantes e a quem é preciso recorrer para marcar posição através do repúdio e abjeção. Como explica Maria do Mar Pereira, trata-se de gerir «activamente o comportamento de forma a evitar associações desse tipo», mas também de monitorizar «o comportamento dos outros» $(2009,122)$.

Os rapazes sabem o que é esperado deles em termos de expetativas da masculinidade e reagem a isso de modos diversos, sendo a forma dominante a demonstração pública e consecutiva das expressões da autoridade, força e poder (Ghaill 1996). Aliás, de certo modo, como um sistema de circularidade, a demonstração de força é necessária para não se ser «homossexualizado» (isto é, julgado como «homossexual»). Não se pode deixar de considerar então o caráter ritualizado desses insultos (Pascoe 2007; 2013) que é justificado pelo facto de a interpelação homofóbica tender a diminuir em termos de características (e.g., verbal, física) e intensidade com a idade, como, aliás, demonstram alguns estudos (cf. Poteat e Rivers 2009), não admirando que, muitas vezes, algumas formas de interpelação homofóbica sejam entendidas como «imaturidade» (McCormack 2012).

É óbvio que não pode negligenciar como estes processos são diferentemente vividos por cada rapaz (ou grupos de rapazes), considerando-se, inclusive, diferentes versões de masculinidade - e.g., «masculinidades inquietas» (Silva e Araújo 2007) ou «masculinidades inclusivas» (Anderson 2009), mas estes processos de interpelação parecem ser bastante comuns; os participantes destacam, ainda assim, a sua maior frequência em certos grupos, como «o pessoal do bairro» ou «a comunidade cigana», embora os excertos acima revelem a sua transversalidade. Não significa, ainda, que sejam inexistentes formas de preconceito, discriminação, ou bullying especificamente dirigidas a identidades não-heterossexuais femininas (bissexuais ou lésbicas); simplesmente, a expressividade antigay aqui é muito mais visível e ativa. 


\section{A questão da intencionalidade: «Esses nomes, e isso, é sem maldade!»}

Ainda assim, estes discursos têm que ser vistos numa ótica mais complexa de dinâmica homofóbica, o que revela também a potencial inadequação do conceito de «bullying homofóbico». Ainda que os rapazes mobilizem insultos homofóbicos, eles sublinham que a sua intenção não é magoar quem, de facto, é homossexual, não sendo de estranhar que, grosso modo, os rapazes façam uma separação ética entre o «bullying homofóbico» (que eles entendem como um particular tipo de bullying contra homossexuais) e os usos de linguagem homofóbica que eles tendem a desconsiderar como «homofóbica»:

Rui - Imagine, eu estou aqui entre amigos com quem convivo há muito tempo e às vezes digo: «Oh, és um paneleiro, tu, eu sei o que é que tu queres!» [o grupo em peso solta uma gargalhada] e, na realidade, ele, por exemplo, namora com uma rapariga e eu só digo isto para brincar. Não estou a ser homofóbico. É uma maneira de pegar com ele. É uma brincadeira como outra qualquer.

Pedro - Isso não quer dizer obrigatoriamente que uma pessoa seja homofóbica; agora, se gozam com isso [com a homossexualidade], já é diferente...

Rafael - Se gozam, é homofóbico. (GDF1, Escola Roxa)

Em certa medida, os rapazes reconhecem que muita dessa expressividade homofóbica é, sobretudo, performativa e até involuntária. Trata-se do que Pascoe (2007) denominou de "fag discourse», um determinado tipo de discurso sobre uma potencial identidade homossexual que funciona mais como um mecanismo disciplinador, que recorre à identidade homossexual como um rótulo simbólico que pode ser aplicado a qualquer um, independentemente do objeto do discurso se identificar ou ser identificado como homossexual (Pereira 2009). Neste sentido, é importante considerar a questão da «intencionalidade» na análise dos processos de dinâmica homofóbica sob pena da perpetuação de algum essencialismo. Kehily e Nayak (1997) já haviam notado que o humor é uma parte substancial da interação entre os rapazes:

Jorge - Paneleiros, larilas, roto. Essas coisas fazem parte... Não significa que se é contra os homossexuais, ou isso; é uma forma de tratamento, vamos dizer assim...

Hugo - Ou seja, não é por causa da homossexualidade do outro.

Jorge - Nada a ver. Nós nem estamos a pensar nisso... É só uma forma de chamar: «Ei, tu, ó paneleiro [o grupo ri-se]. (GDF2, Escola Bege)

Não se pode deixar de considerar um aspeto indireto desta expressividade que é desocultado pelas raparigas: segundo elas, os rapazes utilizam esta forma de interpelação sobretudo como uma estratégia de enaltecimento da sua própria masculinidade (simbolicamente) heterossexual ou, como elas dizem, "para se 
armarem». McCormack utiliza aqui o termo de «recuperação heterossexual», que ele define como «uma ferramenta heurística para compreender as estratégias que os rapazes usam para estabelecer e manter identidades heterossexuais sem invocar homofobia» $(2012,90)$. Em muitos momentos, os/as jovens esclarecem que o reconhecimento prévio de alguém como «homossexual» tende a evitar os usos da linguagem homofóbica:

Rafael - As pessoas usam esses nomes, mas se alguém souber que alguém é [homossexual], as pessoas respeitam.

Mariana - Sim, tendem a não chamar, a controlarem-se mais... (GDF1, Escola Roxa)

A mobilização do insulto parece derivar mais de convenções culturais involuntariamente convocadas a partir de palavras ou expressões que preexistem numa cultura homofóbica - e que podem virar um recurso tácito - do que propriamente revelar intenções particulares de homofobia sobre sujeitos particulares (McCormack 2012). Ora, se um dos elementos definitórios de bullying se carateriza por uma intencionalidade em magoar outrem e se há um discurso dominante, por parte dos rapazes, de que esta linguagem homofóbica não visa magoar quem é (ou melhor, quem se declara) homossexual, o termo bullying torna-se insuficiente para captar esta dimensão particular de violência.

Isto não significa, porém, negligenciar os efeitos regulatórios que a linguagem homofóbica exerce sobre as possibilidades identitárias de jovens LGBTI nem tampouco as múltiplas estratégias através das quais as pessoas podem recorrer a insultos homofóbicos de má-fé. Referindo que uma das formas mais comuns de vitimização homofóbica relatada pela maioria dos/as jovens LGBT é, de facto, através de insultos homofóbicos, Rivers (2011) esclarece que estes se referem sempre a identidades homossexuais produzindo o que se deve pensar sobre homossexuais em termos profundamente desqualificantes (reconhecidos por todos/as), com consequências para jovens LGBTI, em particular em processo de descoberta da sua sexualidade. Como reconhece o Diogo e a Sara secunda:

Diogo - Pelo que vejo, pelo que vejo no dia-a-dia, sim, há situações em que rapazes mais novos e até mesmo na nossa idade, mesmo entre colegas, costumam não ser muito compreensivos quanto a essa questão [da homossexualidade] e às vezes não sabem que estão a afetar os outros psicologicamente e passa como uma brincadeira e a outra pessoa, por vezes, não leva assim, e pode ficar afetada, e os outros pensam que não é nada de sério, mas pode levar a situações graves e lesões na própria pessoa. (GDF3, Escola Cinzenta)

Sara - Os rapazes estão constantemente a chamarem-se de gays e isso. Às vezes coisas piores. Não é por mal, mas para quem é [gay], se calhar é mau porque leva a mal. Pode-se estar a magoar alguém mesmo sem querer... (GDF1, Escola Vermelha) 
O que torna os epítetos homofóbicos tão poderosos é a possibilidade de serem mobilizados com a desculpa constante da sua não-homofobia. Como não existe um imaginário «heterofóbico» que funcione como uma contraposição simbólica, há um grupo que é interpelado sem possibilidade de contestação. Um dos problemas associados à intervenção contra a linguagem homofóbica é que, decorrente de uma noção monolítica da homofobia vinculada ao «insulto direto» e à «agressão física», essa linguagem tende a ser encarada como uma «brincadeira» inofensiva, sobretudo num contexto contemporâneo em que qualquer crítica à linguagem discriminatória é geralmente descartada sob a alçada retórica do «politicamente correto» e do direito relativista à «liberdade de expressão». Decorrente desse aspeto, tende-se a negligenciar a censura a epítetos homofóbicos e, como consequência, passa-se a naturalizar a linguagem homofóbica no contexto escolar.

\section{Comportamentos e estereótipos de género: o discurso «gay, mas não bicha»}

Uma das críticas ao termo bullying homofóbico é o esquecimento da dimensão do «género» como uma performance, ou seja, uma expressão de masculinidades e feminilidades, elas próprias fundadas em noções arquetípicas (Butler 1990; Meyer 2008; Pereira 2009). Os insultos homofóbicos não são apenas mobilizados de forma aleatória, como brincadeira não-intencional. São acionados sobretudo quando alguém não cumpre as «normas de género»e, sobretudo, quando alguém as transgride - ou seja, se situa nas margens da «matriz heterossexual» de Butler (1990) como o centro gravitacional através do qual a orientação sexual e os comportamentos de género são diametralmente regulados. Aí a enunciação das identidades homossexuais, transferidas do domínio privado da sexualidade para a esfera pública, sob a forma do insulto, anexam-se a estereótipos de género, o que acaba por produzir um imaginário homofóbico que regula as condições de afirmação identitária, usufruto de direitos e possibilidades de participação de jovens LGBTI. Uma parte importante desse imaginário implica representações e estereótipos sobre identidades homossexuais envolvendo sobretudo comportamento de género (Passani e Debicki 2016). Uma pesquisa de Passani e Debicki (2016) revela como os estereótipos de género sobre lésbicas e gays tendem ainda a ser muito fortes e enraizados.

Estudos etnográficos em contexto escolar têm revelado que a expressividade homofóbica parece ser imediatamente invocada quando as (hetero)normas (implícitas) de género - «homem masculino» e «mulher feminina» - tendem a ser quebradas ou, pelo menos, não executadas de forma tradicional (Thorne 1993; Pereira 2009), sendo particularmente expressiva nos processos de construção performativa das masculinidades simbolicamente heterossexuais (Rocha e Ferreira 2002; Pascoe 2007; Silva e Araújo 2007). Existem bastantes casos de jovens nas escolas, sobretudo rapazes, que são reconhecidos por todos/as os/as jovens dos grupos por 
causa dos seus comportamentos de género não-normativos, independentemente da sua orientação. Como refere Viviana:

Então nos rapazes [o bullying homofóbico] ainda é pior! Se houver um rapaz que seja [homossexual] e tenha assim uns tiques e isso, metem-no logo para canto. Nem andam com ele nem nada. (GDF2, Escola Amarela)

Ainda assim é preciso considerar que os estereótipos de género apenas se tornam particularmente problemáticos quando são parte constitutiva de discursos monolíticos e objetificadores. Em muitos casos, a sua desconstrução pode servir também para garantir a aparência heteronormativa do meio, estando ao serviço da própria homofobia. É verdade que o comportamento de género e a orientação sexual são dimensões separáveis, mas não se pode esquecer que muitos/as jovens homo e bissexuais transgridem, de facto, as (hetero)normas de género e são estes/ as que se encontram numa condição de maior vulnerabilidade.

De facto, é preciso considerar que, ao contrário do que os discursos de desconstrução dos estereótipos de género parecem pressupor, os/as jovens não estão desinformados/as ao ponto de não saberem a distinção entre «expressão de género» e «orientação sexual». Muitos rapazes são capazes de reconhecer, por exemplo, que existem homens homossexuais com e sem tiques e a prova disso é o discurso constante do «aceito os gays, mas não «as bichas»» em que a «bicha» é descrita como um determinado tipo de «homem homossexual» cujo comportamento de género não só falha em expressar o modelo dominante da masculinidade como também transmite uma ideia de feminilidade arquetípica (cf. Santos 2013). Como refere o Rui: «Eu não tenho nada contra os gays. Tenho é contra as bichas. Aquele que gostam de se pavonear e isso. Não gosto. Detesto» (GDF1, Escola Roxa).

Kathleen Elliot (2012) explica como jovens na escola podem aceitar determinadas identidades homossexuais e rejeitar outras quando estas se tornam simbolicamente mais visíveis, constatando que enquanto certos rapazes homossexuais podiam ser perfeitamente integrados nas atividades escolares, e até usufruir de um elevado grau de popularidade, outros/as, precisamente por serem mais estereotipados (em termos de comportamento de género, preferências ou posições ativistas), eram geralmente excluídos. Não é, então, possível falar-se de «identidades homossexuais» como um marcador identitário por si só: é preciso adicionar a componente da sua homossexualidade assumida e reconhecida, mas sobretudo considerar o comportamento de género como um fator de opressão de forma simultânea, e talvez mais intensa, à orientação sexual, como muitos/as jovens reconhecem:

Ana - Acho que o problema não é ser gay, ser lésbica, ou isso; se a pessoa é [homossexual], quem é que vai saber? O problema é não seguir a norma, tipo, ouvir determinado tipo de música, o vestuário...

Dalila [completa] - Os tiques! O problema até é ter tiques... (GDF2, Escola Bege) 
É curioso reparar que esse repúdio às «bichas» é menos (ou nada) comum entre as raparigas, sendo que o seu inverso (isto é, raparigas lésbicas/bis «masculinas») não suscita tanto aparato ou repúdio:

Rita - Os rapazes sentem-se mais inseguros na sua masculinidade quando veem um homossexual assim com mais tiques. Se não tiver tiques até passa, ninguém diz nada, até podem descobrir que é, mas como não tem, é na boa; agora, se tiver, gozam logo! Parece que os ofende! (GDF2, Escola Bege)

O que é perturbador não é só o comportamento de género não-normativo per si, mas sobretudo a feminilidade nos homens. A feminilidade arquetípica continua a ser símbolo de fragilidade e fraqueza não representando um motivo de orgulho quando reafirmado. Amâncio (1994) explica essa inferioridade associada à feminilidade num estudo onde demonstra que à feminilidade as pessoas tendiam a atribuir caraterísticas negativas e socialmente menos valorizadas. Cardona et al. (2015) realçam que o género ainda tende a ser concebido através de uma racionalidade dicotómica e internamente hierárquica onde ao modelo dominante da feminilidade está usualmente reservado um papel inferiorizante. Sendo o bullying homofóbico um fenómeno predominantemente masculino, não admira então que sejam os homens não-heterossexuais considerados «bichas» - e não os masculinos ou «discretos» - a constituírem-se como os perfeitos bodes expiatórios para o bullying homofóbico que é homofóbico não porque atinge todas as identidades (com base em orientações) homossexuais, mas sobretudo aquelas que fogem às (hetero)normas de género.

\section{Considerações finais}

Espera-se que este artigo possa contribuir para uma análise crítica dos processos de reprodução da homofobia e da heteronormatividade nas (e das) escolas que ainda condicionam o acesso a uma cidadania plena. Era um dos objetivos aprofundar o conhecimento sobre bullying homofóbico nas escolas em Portugal, a partir de uma pesquisa qualitativa alicerçada nas representações e experiências de jovens alunos/as nas escolas públicas do ensino secundário. Os discursos destes/ /as jovens revelam como a «expressão de género» é uma dimensão crucial para compreender os processos de violência homofóbica na escola, um fenómeno que transcende a definição estrita de bullying enquanto fenómeno intencional recorrente e que envolve diferencial de poder (Furlong et al. 2010).

Desde logo, e sendo verdade que parece existir por parte dos/as jovens uma consciência crítica e negativa sobre o bullying homofóbico - enquanto violência, real ou simbólica, dirigida contra pessoas homo e bissexuais -, parece também haver um certo «ritual» masculino do insulto homofóbico generalizado e quotidiano. Este insulto assume, como se viu, a natureza de um fag discourse (Pascoe 
2007) enquanto instrumento disciplinador e regulador da masculinidade. Os rapazes usam-no como forma de agressão, em jeito de brincadeira, e expressam até a ideia de que «nunca» o fariam se o «outro» fosse homossexual. A questão da intencionalidade parece, pois, ser central neste processo. No entanto, sendo verdade que esta linguagem homofóbica pode não ter uma intenção primariamente agressiva, seguramente configura um espaço (público) em que «ser homossexual» é menorizado de forma sistemática, limitando assim a expressão da pluralidade de formas de vivência da sexualidade, da cidadania e sobretudo da identidade. Esta menorização cidadã resulta, quase inevitavelmente, na assunção de estratégias de camuflagem, a que nos referimos num trabalho publicado há 25 anos (Menezes e Costa 1992), que acabam por resultar na invisibilização da diversidade e no reforço da homofobia.

Ainda que hoje em dia se fale em processos de maior abertura à diversidade, a verdade é que a homofobia, nestes termos, continua a marcar presença assídua e pontual na escola, sendo parte estrutural do sistema. Em certa medida, pode-se perspetivar o bullying homofóbico como um ritual institucionalizado de construção da masculinidade. Não significa que não haja bullying motivado por aspetos que não relacionados com género ou formas de homofobia que não envolvam algum tipo de tensão com a masculinidade, mas a expressividade maior de homofobia no estudo em questão depende, na verdade, de processos de construção da masculinidade no interior das normas dominantes da «matriz heterossexual» (Butler 1990).

No processo de construção das escolas como espaços de vivência cidadã quotidiana para todos/as, este estudo desafia quer os/as investigadores/as, quer os/as profissionais de educação a comprometerem-se com o bem-estar de todos/ as, questionando de forma igualmente sistemática esse imaginário homofóbico e genderizado que persiste no espaço escolar. Assim visto, tanto a violência homofóbica quanto o geralmente designado bullying homofóbico devem ser lidos a partir de uma conceção universalista que reconhece estes fenómenos como atentando contra os direitos e a cidadania de todos/as nós.

\section{Referências bibliográficas}

Amâncio, Lígia. 1994. Masculino e feminino: A construção social da diferença. Porto: Edições Afrontamento.

Anderson, Eric. 2009. Inclusive masculinity: The changing nature of masculinities. London: Routledge.

António, Raquel, Tiago Pinto, Catarina Pereira, Diana Farcas, e Carla Moleiro. 2012. «Bullying homofóbico no contexto escolar em Portugal». Psicologia 26 (1): 17-32. DOI: https://doi.org/10.17575/rpsicol.v26i1.260

Bloor, Michael, Jane Franland, Michelle Thomas, e Kate Robson. 2001. Focus Groups in Social Research. London: Sage. DOI: https://doi.org/10.4135/9781849209175 
Braun, Virginia, e Vitoria Clarke. 2006. «Using thematic analysis in psychology». Qualitative Research in Psychology 3 (2): 77-101. DOI: https://doi.org/10.1191/1478088706qp063oa

Butler, Judith. 1990. Gender trouble: Feminism and the subversion of identity. New York: Routledge Falmer.

Cardona, Maria João, Conceição Nogueira, Cristina C. Vieira, Marta Uva, e Teresa-Cláudia Tavares. 2015. Guião de Educação Género e Cidadania: Pré-escolar. Lisboa: Comissão para a Cidadania e Igualdade de Género.

Carneiro, Nuno Santos, e Isabel Menezes. 2007. «From an oppressed citizenship to affirmative identities». Journal of Homosexuality 53 (3): 65-82. DOI: https://doi.org/10.1300/ J082v53n03_05

Connell, Raewyn. 1995. Masculinities. Cambridge: Polity Press.

Costa, Paulo, José Pinto, Henrique Pereira, e Beatriz Pereira. 2015. «Bullying genérico e homofóbico no contexto escolar». Psychology, Community and Health 4 (3): 145-155. DOI: https://doi.org/10.5964/pch.v4i3.122

Elliot, Kathleen. 2012. The right way to be gay: How school structures sexual inequality». In Sexualities in education: A reader, editado por Erica Meiners e Therese Quinn, 158-167. New York: Peter Lang.

Farquhar, Clare, e Rita Das. 1999. «Are focus groups suitable for 'sensitive' topics?». In Developing Focus Group Research: Politics, Theory and Practice, editado por Rosaline Barbour e Jenny Kitzinger, 47-63. London: Sage.

Formby, Eleanor. 2015. «Limitations of focussing on homophobic, biphobic and transphobic 'bullying' to understand and address LGBT young people's experiences within and beyond school». Sex Education 15 (6): 626-640. DOI: https://doi.org/10.1080/14681811 .2015.1054024

Furlong, Michael, Jill Sharkey, Erica Felix, Diane Tanigawa, e Jennifer Greif-Green. 2010. «Bullying assessment: A call for increased precision of self-reporting procedures». In The international handbook of school bullying, editado por Shane Jimmerson, Susan Swearer e Dorothy Espelage, 329-346. New York: Routledge.

Ghaill, Máirtín Mac an. 1996. The making of men: masculinities, sexualities and schooling. Buckingham: Open University Press.

Habermas, Jürgen (1995). «O Estado-Nação europeu frente aos desafios da globalização». Novos Estudos Cebrap 43, 87-101.

Junqueira, Rogério Diniz. 2009. «Homofobia nas escolas: um problema de todos». In Diversidade Sexual na Educação: problematizações sobre a homofobia nas escolas, organizado por Rogério Junqueira, 13-51. Brasília: UNESCO.

Kehily, Mary Jane, e Anoop Nayak. 1997. «'Lads and Laughter': Humour and the production of heterosexual hierarchies». Gender and Education, 9 (1): 69-88. DOI: https://doi. org/10.1080/09540259721466

Kimmel, Michael, e Matthew Mahler. 2003. « Adolescent masculinity, homophobia, and violence ». American Behavioral Scientist 46, 1439-1458.

Louro, Guacira L. (2001). Currículo, género e educação. Porto: Porto Editora.

McCormack, Mark. 2012. The Declining Significance of Homophobia: How Teenage Boys are Redefining Masculinity and Heterosexuality. New York: Oxford University Press. DOI: https://doi.org/10.1093/acprof:oso/9780199778249.001.0001

Menezes, Isabel, e Maria Emília Costa. 1992. «Amor entre iguais: a Psicoterapia da diferença». Cadernos de Consulta Psicológica 8: 79-84.

Meyer, Elizabeth. 2008. «A feminist reframing of bullying and harassment: Transforming schools through critical pedagogy». McGill Journal of Education 43 (1): 33-48. DOI: https://doi.org/10.7202/019572ar 
Meyer, Elizabeth. 2010. Gender and sexual diversity in schools. New York: Springer. DOI: https://doi.org/10.1007/978-90-481-8559-7

Minton, Stephen James, Torunn Dahl, Astrid Mona O’ Moore, e Donnely Tuck. 2008. «An exploratory survey of the experiences of homophobic bullying among lesbian, gay, bisexual and transgendered young people in Ireland». Irish Educational Studies 27 (2): 177-191. DOI: https://doi.org/10.1080/03323310802021961

Monk, Daniel. 2012. «Challenging homophobic bullying in schools: the politics of progress». International Journal of Law in Context 7 (2): 181-207. DOI: https://doi.org/10.1017/ S1744552311000061

Nogueira, Conceição, e João Manuel Oliveira, orgs. 2010. Estudo sobre a discriminação em função da orientação sexual e da identidade de género. Lisboa: Comissão para a Igualdade de Género. Disponível em http://www.igualdade.gov.pt/images/stories/documentos/ documentacao/publicacoes/Estudo_OrientacaoSexual_IdentidadeGenero.pdf

Pascoe, Cheri Joe. 2007. Dude, you're a fag. Masculinity and sexuality in high school. California: University of California Press.

Pascoe, Cheri Joe. 2013. «Notes on a sociology of bullying: Young men's homophobia as gender socialization». QED: A Journal in GLBTQ Worldmaking 1: 1-18.

Passani Antonella, e Marie Debicki. 2016. «Students opinions and attitudes toward LGBT persons and rights: Results of a transnational European project». Journal of LGBT Youth 13 (1-2): 67-88. DOI: https://doi.org/10.1080/19361653.2015.1087927

Pereira, Maria do Mar. 2009. «Fazendo género na escola: uma análise performativa da negociação do género entre jovens». Ex æquo 20: 113-127.

Poteat, Paul, e Ian Rivers. 2010. «The use of homophobic language across bullying roles during adolescence». Journal of Applied Developmental Psychology 3 (2): 166-172. DOI: https://doi.org/10.1016/j.appdev.2009.11.005

Poteat, Paul, Ethan Mereish, Craig DiGiovanni, e Jillian Scheer. 2013. «Homophobic bullying». In Bullying. Experiences and discourses of sexuality and gender, editado por Ian Rivers e Neil Duncan, 75-90. New York: Routledge.

Rivers, Ian. 2011. Homophobic bullying: Research and theoretical perspectives. Oxford: Oxford University Press. DOI: https://doi.org/10.1093/acprof:oso/9780195160536.001.0001

Rocha, Cristina, e Manuela Ferreira. 2002. «Aprender a ser rapaz entre rapazes e raparigas: Masculinidades em duas escolas $\mathrm{C}+\mathrm{S}$ do distrito do Porto». Trabalhos de Antropologia e Etnologia 42 (1-2): 49-68.

Rodrigues, Liliana, Rita Grave, João Manuel Oliveira, e Conceição Nogueira. 2016. «Study on homophobic bullying in Portugal using Multiple Correspondence Analysis (MCA)». Revista Latinoamericana de Psicología 48 (3): 191-200. DOI: https://doi.org/10.1016/j. rlp.2016.04.001

Santos, Hugo (2013). Um desvio na corrente que(er)stionando as margens: Percursos escolares e culturas juvenis de rapazes não-heterossexuais. Dissertação de Mestrado. Faculdade de Psicologia e de Ciências da Educação da Universidade do Porto.

Silva, Sofia Marques. 2010. «Estudantes e jovens em contexto escolar. Contributos da Sociologia da Educação para o estudo das juventudes». In Tendências e controvérsias em Sociologia da Educação, organizado por Pedro Abrantes, 79-100. Lisboa: Editora Mundos Sociais.

Silva, Sofia Marques, e Helena Costa Araújo. 2007. «Interrogando as masculinidades em contexto escolar: Mudança anunciada?» Ex aequo 15: 89-117.

Thorne, Barrie. 1993. Gender play: boys and girls in school. New Brunswick: Rutgers University Press. 
UNESCO. 2012. Review of homophobic bullying in educational institutions. Disponível no endereço http://unesdoc.unesco.org/images/0021/002157/215708e.pdf [Consultado em 1 de maio de 2017].

Wilkinson, Sue. 1999. «Focus Group: A Feminist Method». Psychology of Women Quarterly 23 (2): 221-244. DOI: https://doi.org/10.1111/j.1471-6402.1999.tb00355.x

Hugo M. Santos. Licenciado e mestre em Ciências da Educação, bolseiro de doutoramento da FCT no Programa Doutoral em Ciências da Educação na FPCE-UP. A sua investigação centra-se no bullying homofóbico, diversidade LGBTI e educação sexual numa perspetiva de cidadania e igualdade de direitos. Tem apresentado trabalhos sobre estas temáticas. Participou ativamente em movimentos LGBTI.

Endereço eletrónico: hmiguel_s@hotmail.com

Sofia Marques da Silva. Doutorada em Ciências da Educação e professora auxiliar da FPCEUP. Desenvolve investigação sobre desigualdades, jovens, género e diversidade no campo educacional, com publicações e direção de projetos inter/nacionais. Tem estado envolvida em organizações internacionais (EERA, EACEA) e é deputy in chief do Journal Ethnography \& Education (2018-2023). Coordena o eixo Inclusão da iniciativa Portugal INCoDe.2030.

Endereço eletrónico: sofiamsilva@fpce.up.pt

Isabel Menezes. Doutorada em Psicologia e agregada em Ciências da Educação, é Professora Catedrática no Departamento de Ciências da Educação da Faculdade de Psicologia e Ciências da Educação da Universidade do Porto. Coordena projetos sobre a participação cívica e política de crianças, jovens e adultos e o seu papel no empoderamento de grupos em risco de exclusão em função do género, da orientação sexual, do estatuto de imigrante ou da incapacidade.

Endereço eletrónico: imenezes@fpce.up.pt

Artigo recebido a 31 de maio de 2017 e aceite para publicação a 04 de agosto de 2017. 